\title{
The Day I Receive My Ph.D.
}

\section{Arkaye Kierulf}

I'll head out into the streets to hand out

My dissertation abstract like discount-hotel flyers.

For Christmas I'll send copies of my diploma to my aunts in Florida

as a token of affection.

Maybe I'll stroll down into city hall and quiz the barber

On the mysteries of Minkowskian space and the quantum dot.

I'll call the Mayor and invite him to a glass of wine to discuss

The staggering implications of my spectral discoveries

While in the distance prepubescent goats cavort in the everglades

under the sun.

I think I'll fly to the Pacific to wrap little baby whales with my Ph.D.

And proclaim to all my fellow sufferers, "By the power vested in me By the Great Universities of the West and the East, I celebrate

All our great sins and harbor in my heart all our small-limbed

affections."

I'll wear a flowing toga and carry a scepter made of green tuft.

Searching for the meaning of life, a monk will find it in a footnote

On page 873 of an unpublished treatise found after my death

Inside my medicine cabinet, beside the oatmeal cookies.

In crowds I'll secretly laugh to myself, having just

Mapped out Lacan's topology in my mind.

I'll talk a little Latin or Celtic to women,

And their bras will unhook themselves,

Welcoming me into the warmth of their fold.

I'll trace the arc of Mercury, compute the angle

Of the zodiac from the window, and plot

The erratic flight of bees.

I'll send off little paper airplanes

To the moon. Forge world peace. Vanish

On a long journey far up into the Himalayan mountains

To talk to the Gods. I will try to live forever,

If only for a little while.

USA

e-mail: ak737@cornell.edu

Publisher's Note Springer Nature remains neutral with regard to jurisdictional claims in published maps and institutional affiliations. 